\title{
Simultaneous partial nitrification and 2-fluorophenol biodegradation with aerobic granular biomass: Reactor performance and microbial communities
}

\author{
Carlos Ramos $^{\mathrm{a}, *}$, Catarina L. Amorim ${ }^{\mathrm{b}, \mathrm{c}}$, Daniela P. Mesquita ${ }^{\mathrm{d}}$, Eugénio C. Ferreira ${ }^{\mathrm{d}}$, Julián Carrera ${ }^{\mathrm{a}}$, \\ Paula M.L. Castro ${ }^{\mathrm{b}}$ \\ ${ }^{a}$ GENOCOV Research Group, Department of Chemical, Biological and Environmental Engineering, School of Engineering, Universitat Autònoma de Barcelona, Ed. Q - Campus \\ UAB, 08193 Bellaterra, Barcelona, Spain \\ ${ }^{\mathrm{b}}$ Universidade Católica Portuguesa, CBQF - Centro de Biotecnologia e Química Fina e Laboratório Associado, Escola Superior de Biotecnologia, Rua Arquiteto Lobão Vital, \\ Apartado 2511, 4202-401 Porto, Portugal \\ ${ }^{\mathrm{c}}$ Departamento de Biologia e Centro de Estudos do Ambiente e do Mar (CESAM), Universidade de Aveiro, Aveiro 3810-193, Portugal \\ ${ }^{\mathrm{d}}$ CEB - Centre of Biological Engineering, Universidade do Minho, Campus de Gualtar, 4710-057 Braga, Portugal
}

\section{H I G H L I G H T S}

- Nitritation and biodegradation of 2fluorophenol were achieved in granular reactor.

- Stable aerobic granules were maintained 135 days in a sequencing batch reactor.

- 2-Fluorophenol feeding decreased the species richness.

- The microbial community changed by treating 2-fluorophenol.

- Aerobic granular reactors are a promising technology for industrial wastewaters.

\section{A R T I C L E I N F O}

\section{Article history:}

Received 1 February 2017

Received in revised form 24 March 2017

Accepted 28 March 2017

Available online 30 March 2017

\section{Keywords:}

Granulation

Bioaugmentation

Nitritation

Phenolic compound

Molecular biology
G R A P H I C A L A B S T R A C T

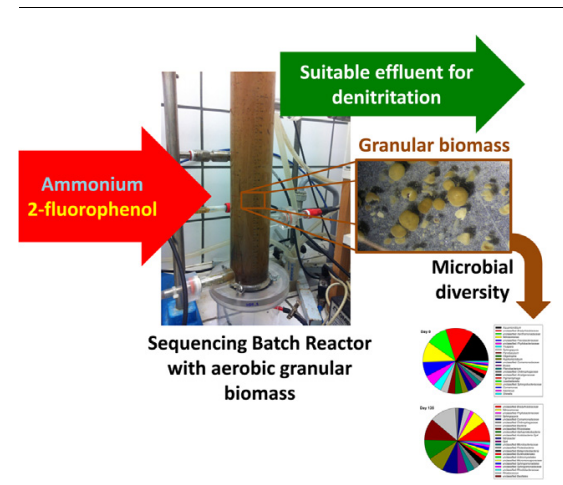

\begin{abstract}
A B S T R A C T
An aerobic granular bioreactor was operated for over 4 months, treating a synthetic wastewater with a high ammonium content $\left(100 \mathrm{mg} \mathrm{N} \mathrm{L}^{-1}\right)$. The inoculum was collected from a bioreactor performing simultaneous partial nitrification and aromatic compounds biodegradation. From day-56 onwards, 2fluorophenol (2-FP) (12.4 $\mathrm{mg} \mathrm{L}^{-1}$ ) was added to the feeding wastewater and the system was bioaugmented with a 2-FP degrading bacteria (Rhodococcus sp. FP1). By the end of operation, complete 2-FP biodegradation and partial nitrification were simultaneously achieved. Aerobic granules remained stable over time. During the 2-FP loading, a shift in the community structure occurred, coinciding with the improvement of 2-FP degradation. DGGE analysis did not allow to infer on the bioaugmented strain presence but pyrosequencing analysis detected Rhodococcus genus by the end of operation. Together with other potential phenolic-degraders within granules, these microorganisms were probably responsible for 2-FP degradation.
\end{abstract}

(c) 2017 Elsevier Ltd. All rights reserved.

\footnotetext{
* Corresponding author.

E-mail address: carlosantonio.ramos@uab.cat (C. Ramos).
} 


\section{Introduction}

Industrial activities have led to the widespread production and release of xenobiotic compounds (such as aromatic compounds) and ammonium (Kim and Kim, 2003; Milia et al., 2012) to rivers and water bodies. The decontamination of effluents containing such compounds is not an easy task because the applied treatment processes can be inefficient and/or not cost-effective. Nowadays, physico-chemical and biological processes are applied to treat industrial wastewaters containing aromatic compounds. Commonly, physico-chemical processes are expensive and often cannot achieve complete removal of the aromatic compounds and may lead to the generation of toxic by-products (Al-Khalid and ElNaas, 2012). On the contrary, biological processes can achieve complete degradation of the aromatic compounds, and are costeffective and usually more environmentally friendly (Al-Khalid and El-Naas, 2012). However, the efficiency of biological processes can be negatively affected by the presence of aromatic compounds. A promising technology to overcome related problems is the use of aerobic granular biomass reactors (Adav et al., 2008; Duque et al., 2011; Ramos et al., 2016a). Aerobic granules are dense spherical structures, formed by a microbial self-immobilization process, which have excellent settling ability. The aerobic granular technology is able to: (i) retain high biomass concentration in the reactor, (ii) to withstand high organic loading rates and (iii) to tolerate toxic compounds (Adav et al., 2008).

A feasible technology to treat complex industrial wastewaters composed of aromatic compounds and ammonium can be a twostage biological process, consisting of two different granular reactors: an aerobic granular reactor and an anoxic granular reactor. In the first stage, the aerobic granular reactor performs simultaneous partial nitrification (oxidation of ammonium to nitrite) and biodegradation of the aromatic compounds. The achievement of partial nitrification instead of full nitrification allows reduce aeration and, consequently, reducing running costs. This aerobic granular reactor was previously used to treat wastewater streams with phenol and phenol substituted with methyl- and nitro- groups ( $p$ nitrophenol and $o$-cresol) (Jemaat et al., 2014, 2013; Ramos et al., 2016a). However, its performance has not been studied with aromatic compounds with halogen substituents, such as chloride- or fluoride-. In the second stage, nitrite can be reduced by heterotrophic denitrification via nitrite (Ramos et al., 2016b).

Fluorophenols can be found in effluents from agrochemical and pharmaceutical industries (Key et al., 1997). These organic compounds are enzyme inhibitors, modifiers of cell-cell communication and disruptors of membrane transport (Key et al., 1997). Moreover, they are much more resistant to biodegradation than other substituted phenols because of the stability of the carbonfluoride bond (Key et al., 1997).

To the best of the authors' knowledge, simultaneous biodegradation of fluorophenols and partial nitrification in a single reactor has not been reported until now. Besides, biodegradation of fluorophenols is scarcely reported. The related studies on aerobic biodegradation of fluorophenol are related to i) an acclimated activated sludge system operated in batch mode (Chaojie et al., 2007) and to ii) an aerobic granular reactor treating a readily biodegradable compound (acetate) and bioaugmented with an specific fluorophenol-degrading bacterial strain (Duque et al., 2015, 2011).

The present study aims to achieve simultaneous biodegradation of 2-fluorophenol (2-FP) and partial nitrification in an aerobic granular reactor. The microbial diversity in the aerobic granules at the beginning and at the end of the operation period was assessed, to have a better understanding of the microbial composition, and to evaluate the success of a bioaugmentation strategy with a specific 2-FP-degrading bacterial strain.

\section{Materials and methods}

\subsection{Reactor set up and operation}

A sequencing batch reactor (SBR) of $2.5 \mathrm{~L}$, with an internal diameter of $6.5 \mathrm{~cm}$ and height of $110 \mathrm{~cm}$, was used. The reactor was operated in cycles using an automatic timer (Siemens Logo! 230RC) to start and stop pumps for influent, aeration and effluent withdrawal. Dissolved oxygen (DO) concentration and $\mathrm{pH}$ were measured and controlled online. DO concentration was measured with a DO-sensor (InPro 6820, Mettler-Toledo) and expressed as percentage of the oxygen saturation concentration (100\% is equal to $9.1 \mathrm{mg} \mathrm{O}_{2} \mathrm{~L}^{-1}$ ). Compressed air was introduced from the bottom of the reactor through a diffuser. DO concentration was controlled by an on-off controller. The pH (InPro3030, Mettler-Toledo) was maintained at $8.0 \pm 0.5$ by dosing $1 \mathrm{M} \mathrm{NaOH}$ or $1 \mathrm{M} \mathrm{HCl}$. The influent was introduced from the bottom of the reactor. Temperature was maintained at $30^{\circ} \mathrm{C}$ by means of an external water jacket, which allowed a constant temperature operation.

The reactor was operated in successive cycles, consisting of feeding, aeration, settling and withdrawal. Table 1 shows the operating conditions applied in the SBR. Hydraulic retention time (HRT) was varied by increasing the volume exchange and the reaction time to decrease the applied organic loading rate (OLR) and nitrogen loading rate (NLR).

The reactor was fed with a synthetic wastewater. Depending on the operation conditions and the influent composition, the operation of the reactor was divided into three phases:

i) Phase I (from day-0 to day-35): the reactor was inoculated with aerobic granules from an airlift reactor treating an industrial wastewater and it was operated in batch mode. At day-0 and day-13, ammonium pulses were carried out to reach initial concentrations of 150 and $330 \mathrm{mg} \mathrm{N}^{-\mathrm{NH}_{4}^{+}}$ $\mathrm{L}^{-1}$ in the reactor, respectively.

ii) Phase II (from day-36 to day-55): the reactor was operated as SBR and fed with an influent containing only ammonium $\left(100 \pm 6 \mathrm{mg} \mathrm{N}-\mathrm{NH}_{4}^{+} \mathrm{L}^{-1}\right)$. The HRT varied between 1.2 to 2.5 d.

iii) Phase III (from day-56 to day-135): in this phase, the SBR was fed with an influent containing ammonium (100 $\left.\pm 6 \mathrm{mg} \mathrm{N} \mathrm{L}^{-1}\right)$ and 2-FP (12.4 $\mathrm{mg} \mathrm{L}^{-1}$, representing $23.9 \mathrm{mg} \mathrm{COD} \mathrm{L}^{-1}$ ). At the beginning of this phase (day-56), the SBR was bioaugmented with a specific 2-FP-degrading bacterial strain (Duque et al., 2012). The HRT varied between 2.5 and $5.0 \mathrm{~d}$.

The synthetic wastewater was also composed by micronutrients (expressed as mg L ${ }^{-1}$ ): $41.0 \mathrm{KH}_{2} \mathrm{PO}_{4} ; 176.0 \mathrm{NaCl} ; 198.0 \mathrm{MgCl}_{2^{-}}$ .7 $\mathrm{H}_{2} \mathrm{O} ; 4.0 \mathrm{FeSO}_{4} \cdot 7 \mathrm{H}_{2} \mathrm{O} ; 3.0 \mathrm{MnSO}_{4} \cdot \mathrm{H}_{2} \mathrm{O} ; 4.0 \mathrm{ZnSO}_{4} \cdot 7 \mathrm{H}_{2} \mathrm{O} ; 2.0$ $\mathrm{CuSO}_{4} \cdot 5 \mathrm{H}_{2} \mathrm{O} ; 0.02 \mathrm{H}_{3} \mathrm{BO}_{3} ; 12.0 \mathrm{CO}\left(\mathrm{NH}_{2}\right)_{2}$ and 2.0 yeast extract. Sodium bicarbonate $\left(11.2 \mathrm{~g} \mathrm{NaHCO}_{3} \mathrm{~L}^{-1}\right)$ was added to the influent to ensure enough buffer capacity.

\subsection{Inoculum}

Aerobic granular biomass (5 g VSS, volatile suspended solids) from a continuous airlift reactor treating an industrial wastewater containing ammonium and aromatic compounds was used as inoculum (Ramos et al., 2016a). That aerobic granular reactor performed simultaneous partial nitrification and organic matter removal, achieving complete biodegradation of the organic matter (96\%) and an effluent with $95 \%$ of nitrite and $5 \%$ of nitrate. Some of the characteristics of the aerobic granules were as follows: average granule size of $700 \pm 30 \mu \mathrm{m}$, sludge volumetric index (SVI) at $5 \mathrm{~min}$ 
Table 1

Operating conditions applied in the SBR.

\begin{tabular}{|c|c|c|c|c|c|c|c|c|}
\hline \multirow[t]{2}{*}{ Phase } & \multirow{2}{*}{$\begin{array}{l}\text { Operational time } \\
\text { (d) }\end{array}$} & \multicolumn{7}{|c|}{ Conditions of the cycles } \\
\hline & & $\begin{array}{l}\text { Feeding + Aeration } \\
(\mathrm{min})\end{array}$ & $\begin{array}{l}\text { Aeration } \\
(\mathrm{min})\end{array}$ & $\begin{array}{l}\text { Settling } \\
\text { (min) }\end{array}$ & $\begin{array}{l}\text { Withdrawal } \\
\text { (min) }\end{array}$ & $\begin{array}{l}\text { Reaction volume } \\
\text { (L) }\end{array}$ & $\begin{array}{l}\text { Volume exchange } \\
\text { (\%) }\end{array}$ & $\operatorname{HRT}(d)$ \\
\hline I & $0-35$ & ${ }^{*}$ & - & - & - & 2.1 & - & - \\
\hline II & $36-45$ & 700 & 0 & 15 & 5 & 2.1 & 40 & 1.2 \\
\hline II & $46-48$ & 700 & 0 & 10 & 5 & 2.1 & 40 & 1.2 \\
\hline II - III & $49-63$ & 700 & 725 & 10 & 5 & 2.1 & 40 & 2.5 \\
\hline III & $64-134$ & 700 & 725 & 10 & 5 & 1.6 & 20 & 5.0 \\
\hline
\end{tabular}

Pulse feeding at day-0 and day-13.

of $10.1 \pm 0.5 \mathrm{~mL} \mathrm{~g}{ }^{-1}$ of total suspended solids (TSS) and $\mathrm{SVI}_{30} / \mathrm{SVI}_{5}$ ratio of 1.0. The aerobic granular biomass was stored at $4{ }^{\circ} \mathrm{C}$ for 30 days before the inoculation of the SBR of this study.

\subsection{Bioaugmentation with Rhodococcus sp. strain FP1}

On day-56, the SBR was bioaugmented with Rhodococcus sp. strain FP1, a bacterial strain able to degrade 2-FP as sole carbon and energy source, previously isolated by Duque et al. (2012). FP1 pure cultures were grown in sealed flasks containing a mineral salts liquid medium (Caldeira et al., 1999) and 2-FP, firstly at a concentration of $50 \mathrm{mg} \mathrm{L}^{-1}$ and later of $100 \mathrm{mg} \mathrm{L}^{-1}$. The cultures were incubated on an orbital shaker ( $100 \mathrm{rpm})$ at $25^{\circ} \mathrm{C}$. The optical density at $600 \mathrm{~nm}\left(\mathrm{OD}_{600}\right)$ and fluoride release were followed to monitor growth and 2-FP biodegradation, respectively. The SBR was bioaugmented with $300 \mathrm{~mL}$ of an FP1 pure culture with an $\mathrm{OD}_{600}$ of 0.660 .

\subsection{Analytical methods}

Liquid samples were periodically withdrawn from the influent and effluent of the reactor to determine the concentrations of ammonium, nitrite, nitrate, 2-FP and fluoride ions. Ammonium, nitrite and nitrate concentrations were measured by commercial kits (Merck). 2-FP was analysed by high performance liquid chromatography (HPLC), on a System Gold 126 (Beckman Coulter, Fullerton, USA), with a LiChroCART 25-4 LiChrospher 100 RP-18 reversed-phase column, $5 \mu \mathrm{m}$ particle size (Merck. Darmstadt, Germany), according to the procedure described in Duque et al. (2011). The concentration of fluoride ions in supernatants was measured with an ion-selective combination electrode (model $\mathrm{CH}-8902$, Mettler-Toledo GmbH, Urdorf, Switzerland), according to the procedure described in Duque et al. (2011). Total and volatile suspended solids (TSS and VSS, respectively) were determined according to Standard Methods 2540 D and 2540 E (APHA, 1999).

Periodic samples were taken from the bioreactor during the aeration phase to assess the morphology of the aerobic granules. A volume of $1 \mathrm{~mL}$ was transferred to a Petri dish for visualisation and image acquisition on an Olympus SZ40 stereo microscope (Olympus, Tokyo, Japan) with a total $30 \times$ magnification. The stereo microscope was coupled to a CCD Sony AVD D5CE (Sony, Tokyo, Japan) grey video camera, and to a Data Translation DT 3155 (Data Translation Marlboro, Massachusetts) frame grabber. Image acquisition was performed for $768 \times 576$ pixels and 8 -bit (256 grey levels) format through the Image Pro Plus (Media Cybernetics, Silver Spring, MD) software. In the present case, the granules were divided into two classes based on the equivalent diameter (Deq): intermediate granules (Deq between 0.15 and $1.5 \mathrm{~mm}$ ) and larger granules (Deq above $1.5 \mathrm{~mm}$ ). Calibration from pixels to the metric unit dimensions was performed by means of a micrometer slide, allowing the determination of the metric calibration factor. The collected images were treated by means of specially developed program in Matlab (The Mathworks, Inc., Natick) in order to char- acterise aerobic granules samples, in terms of some relevant morphological parameters as previously described by Mesquita et al. (2009).

\subsection{High-throughput sequencing}

Identification of the microbial population was performed using next-generation sequencing at day- 0 and day-135 of the reactor operation. Samples of the granular biomass were taken from the reactor during the aeration phase. Total genomic DNA of the aerobic granular biomass was extracted and purified using PowerBiofilm $^{\mathrm{TM}}$ DNA Isolation Kit (MoBio Laboratories, USA) in accordance with the manufacturer's instructions. Paired-end sequencing of the extracted DNA was performed on Illumina MiSeq platform by Research and Testing Laboratory (Lubbock, Texas, USA). Bacterial 16S rRNA variable regions V2-V4 were targeted using the primer pair 341F-907R. Biodiversity analysis and phylogenetic classification were performed with the methodology explained in Ramos et al. (2016a). Relative abundances of the reads were determined by taxonomic level. Indices of biological diversity were calculated for day-0 and day-135 libraries (Fig. S1 and Table S1 of the Supporting information), indicating that both libraries were comparable in terms of abundance percentages, and that good coverage of diversity was reached.

\subsection{Denaturing gradient gel electrophoresis (DGGE)}

Genomic DNA from the crushed granules samples was extracted using the UltraClean Microbial DNA Isolation Kit (MO BIO Laboratories, Inc., USA) according to the manufacturer's instructions. The extracted DNA was kept at $-20{ }^{\circ} \mathrm{C}$ until its use for DGGE. The primers 338F-GC and 518R were used for the amplification of the highly variable V3 region of bacterial 16S rRNA gene fragments. The followed procedures for PCR amplification and DGGE were according to Amorim et al. (2014).

\section{Results and discussion}

\subsection{Reactor performance}

The performance of the reactor throughout the 3 phases is shown on Fig. 1. Firstly, the reactivation of the aerobic granules took place (phase I). After inoculation, the reactor was operated in batch mode during 35 days with two ammonium pulses (days 0 and 13, respectively) and high DO concentration (90\%). After each ammonium pulse feeding, it was observed that the ammonium effluent concentration decreased, indicating that the granules' reactivation was successful.

From day-36 onwards, the reactor was operated in SBR mode. During phase II, only ammonium was fed to the SBR. From day36 to day-45, a NLR of $0.08 \mathrm{~g} \mathrm{~N}-\mathrm{NH}_{4}^{+} \mathrm{L}^{-1} \mathrm{~d}^{-1}$ was applied, and most of the entering ammonium was oxidised to nitrate (90\%), whilst only a small part was accumulated as nitrite (1\%) (Fig. 1B). At the 


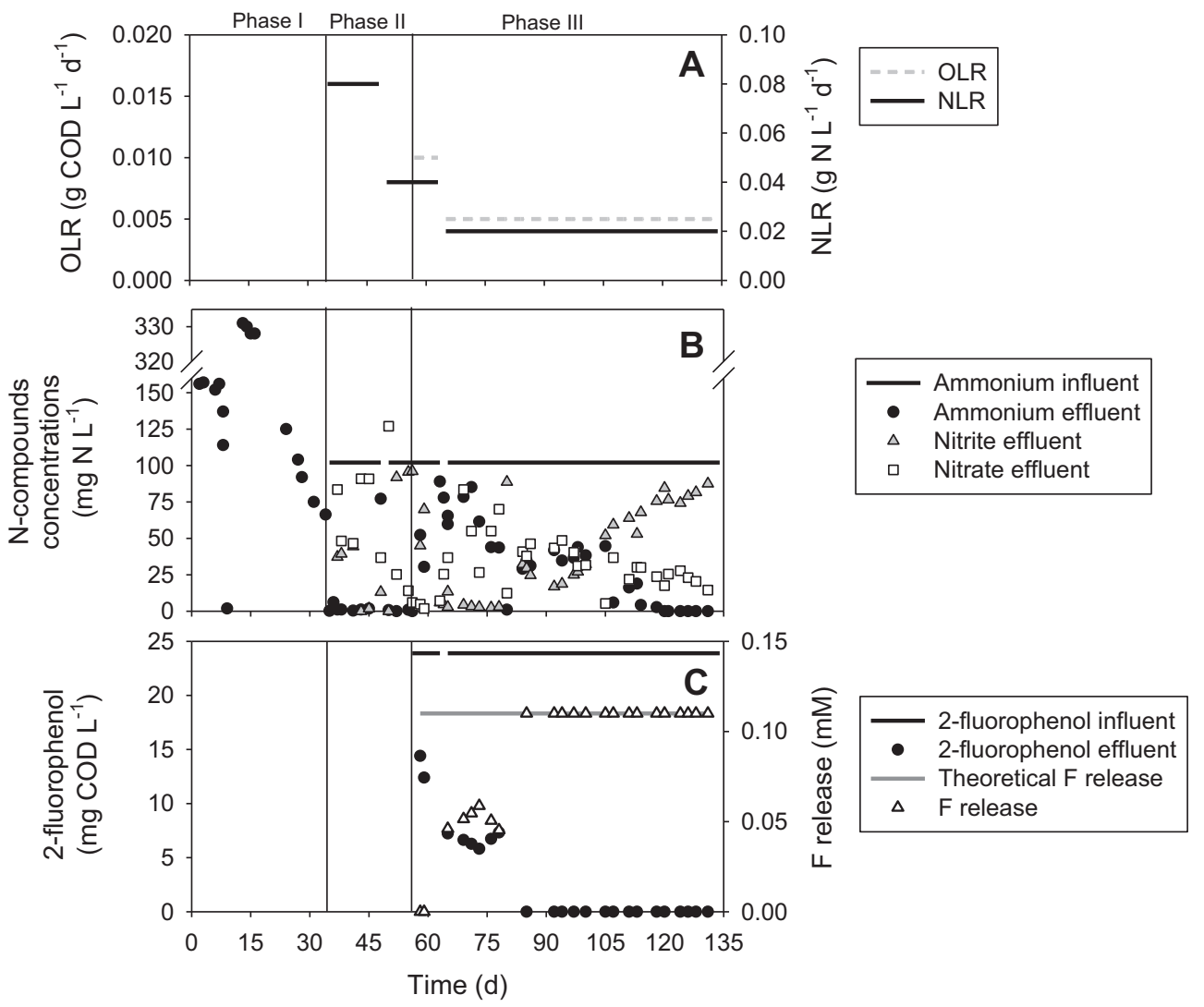

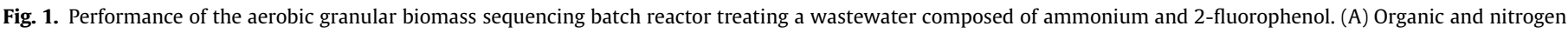
loading rates, (B) concentrations of the nitrogen-compounds and (C) 2-fluorophenol concentrations and fluoride release.

beginning of phase II, the settling time was fixed at $15 \mathrm{~min}$, but from day-45 onwards, the settling time was reduced to $10 \mathrm{~min}$ to maintain a good aerobic granulation. This change produced a momentary accumulation of ammonium (day-47, Fig. 1B), probably due to an excessive washout of biomass from the SBR. Consequently, the feeding was stopped for 2 days to consume the accumulated ammonium and to recover the nitrification efficiency. After achieving complete ammonium consumption on day-50, both NLR and DO concentrations were decreased from 0.08 to $0.04 \mathrm{~g} \mathrm{~N}-\mathrm{NH}_{4}^{+} \mathrm{L}^{-1} \mathrm{~d}^{-1}$ and from 90 to $75 \%$, respectively. These changes produced an improvement of the partial nitrification process. As a result, at the end of phase II, the effluent was composed of 95.9 and $10.0 \mathrm{mg} \mathrm{L}^{-1}$ of nitrite and nitrate, respectively (Fig. 1B). Thus, the oxidation of ammonium changed from almost full nitrification ( $90 \%$ of nitrate) at the beginning of phase II, to partial nitrification ( $90 \%$ of nitrite) at the end of phase II, and this change was essentially due to the decrease of the DO concentration in the SBR. Indeed, despite the loss of biomass after the decrease of the settling time on day- 45 , the biomass concentration in the SBR was stabilised at $1.8 \pm 0.7 \mathrm{~g} \mathrm{VSS} \mathrm{L}^{-1}$ at the end of phase II, and no significant washout of biomass was observed.

At the beginning of phase III (day-56), the SBR was bioaugmented with Rhodococcus sp. strain FP1 able to degrade 2-FP as sole carbon and energy source. Bioaugmentation is the addition of a specialised microorganism or mixed microbial population to a biological reactor to improve the capacity to biodegrade specific compounds, such as toxic/recalcitrant organic compounds (Bartrolî et al., 2011; Duque et al., 2011; Martín-Hernández et al., 2012). Specifically, bioaugmentation with FP1 was previously applied in an aerobic granular reactor performing organic matter biodegrada- tion. That strategy achieved simultaneous biodegradation of acetate and 2-FP in a granular SBR (Duque et al., 2011). However, this strategy has never been applied in a nitrifying reactor for simultaneous partial nitrification and 2-FP biodegradation.

Throughout phase III, 2-FP was introduced into the feeding together with ammonium (Fig. 1C). Despite the bioaugmentation with FP1, 2-FP was poorly biodegraded in the first days of phase III, with $12-14 \mathrm{mg} \mathrm{COD} \mathrm{L}^{-1}$ of 2-FP in the effluent of the reactor. Considering that the applied volume exchange was of $40 \%$ (see Table 1), the 2-FP concentration inside the reactor should be of ca $10 \mathrm{mg} \mathrm{COD} \mathrm{L}^{-1}$ of $2-\mathrm{FP}$, similar to those obtained at the outlet, as such no degradation occurred. The biodegradation of 2-FP can be followed by the stoichiometric fluoride release (Fig. 1C) (Duque et al., 2012; Key et al., 1997). Furthermore, the accumulation of 2-FP in the SBR led to inhibition of nitrification, and resulted in ammonium accumulation (Fig. 1B). The presence of aromatic compounds (phenol, o-cresol and quinoline) affects ammonium oxidation, as have been previously reported in bioreactors with nitritation not starting until the aromatic compounds were completely consumed (Jemaat et al., 2013; Liu et al., 2005; Morita et al., 2007; Ramos et al., 2016a). Thus, the feeding was stopped for a period of 2 days (from day-63 to day-65) to allow the consumption of all the accumulated 2-FP and thereafter of ammonium. Then, both OLR and NLR were decreased from day-65 onwards to $0.02 \mathrm{~g} \mathrm{~N} \mathrm{~L}^{-1} \mathrm{~d}^{-1}$ and $0.005 \mathrm{~g} \mathrm{COD} \mathrm{L}^{-1} \mathrm{~d}^{-1}$, respectively (Fig. 1A). After this change, 2-FP biodegradation started with values around $50 \%$ of the inlet 2-FP amount. From day- 80 onwards, complete 2-FP biodegradation was achieved, as revealed by the stoichiometric fluoride release (Fig. 1C). The 2-FP disappearance from the bulk liquid of the SBR caused a significant improvement 
in the ammonium oxidation (Fig. 1B), showing that 2-FP has a significant inhibitory effect over the nitrification process. From day90 , a clear change between full and partial nitrification can be observed (Fig. 1B), since the major form of nitrogen in the effluent was nitrite instead of nitrate. This change was probably caused by the progressive repression of nitrite-oxidising bacteria (NOB) activity in the SBR. The key operational variable to ensure that ammonium was only oxidised to nitrite (i.e. partial nitrification) in an aerobic granular reactor is the ratio between DO and ammonium concentrations in the bulk liquid ([DO]/[N-NH$\left.{ }_{4}^{+}\right]$) (Bartrolí et al., 2010; Isanta et al., 2015; Reino et al., 2016). The control of this operational parameter allows one to achieve and maintain partial nitrification even at high DO concentration, as previously demonstrated with long-term specific experiments (Bartrolí et al., 2010). In that study, it was determined that full nitritation in a granular reactor was only achieved for $[\mathrm{DO}] /\left[\mathrm{N}-\mathrm{NH}_{4}^{+}\right]$lower than 0.25 . In the present study, the $[\mathrm{DO}] /\left[\mathrm{N}-\mathrm{NH}_{4}^{+}\right]$ratio was not controlled during the SBR operation, thus resulting from the applied operational conditions. Nevertheless, the $[\mathrm{DO}] /\left[\mathrm{N}-\mathrm{NH}_{4}^{+}\right]$ratio varied between 0.10 and 0.15 from day-60 to day- 100 . This value is lower than the threshold value reported by Bartrolí et al. (2010) and thus, nitrite accumulation occurred in the SBR. However, complete repression of the NOB activity was not achieved since the $[\mathrm{DO}] /\left[\mathrm{N}-\mathrm{NH}_{4}^{+}\right]$ratio increased from day-110, because ammonium was almost completely removed from the SBR. In such a case, an automatic control loop would be necessary to ensure an accurate value of the $[\mathrm{DO}] /\left[\mathrm{N}-\mathrm{NH}_{4}^{+}\right]$ratio (Bartrolí et al., 2010; Isanta et al., 2015; Reino et al., 2016).

At the end of the experimental period, aerobic granules were able to completely biodegrade the inlet 2-FP and to oxidise most of the inlet ammonium to nitrite. Thus, an aerobic granular biomass able to simultaneously perform 2-FP biodegradation and partial nitritation was developed.

\subsection{Aerobic granules properties}

The characteristics of the aerobic granular biomass during the operational period are shown in Fig. 2. At day- 0 , the biomass mainly consisted of granules with Deq around $700 \mu \mathrm{m}$ (Fig. 2A). Only a small percentage (lower than $35 \%$ ) of biomass was made up of granules with Deq above $1.5 \mathrm{~mm}$. From phase I till the end of phase II, the number of granules with Deq below 1.5 increased from $64 \%$ to $88 \%$, and a concomitant decrease on the percentage of granules with Deq above $1.5 \mathrm{~mm}$, from $35 \%$ to $11 \%$ was observed (Fig. 2B). The intermediate granules originated from the breakage of the larger granules, which is corroborated by the sharp decrease from $61 \%$ to $23 \%$ of the area percentage (Fig. 2C). Nevertheless, in phase III, during which 2-FP was present in the feeding, the number of granules of each size group was maintained almost constantly until the end of the operational period (Fig. 2B).

The compactness and robustness of the aerobic granules were indicative of the presence of stable granules during the operational period, which indicated that the load of 2-FP did not affect the biomass (Fig. 2D and E), and that the granules did not lose their morphological quality. The absence of filamentous bacteria during the monitoring period by image analysis suggested that the sludge's settling properties were not affected. The fact that the robustness and compactness of the granular sludge were not affected (even though a slight decrease was observed) also corroborates that the sludge presented good settling properties. The properties of the aerobic granules were maintained with almost no change, which is in accordance with the performance of the bioreactor, since no failures in the removal processes were observed even when 2-FP was present in the feeding. The observed results demonstrate the robustness of the system to deal with recalcitrant compounds.

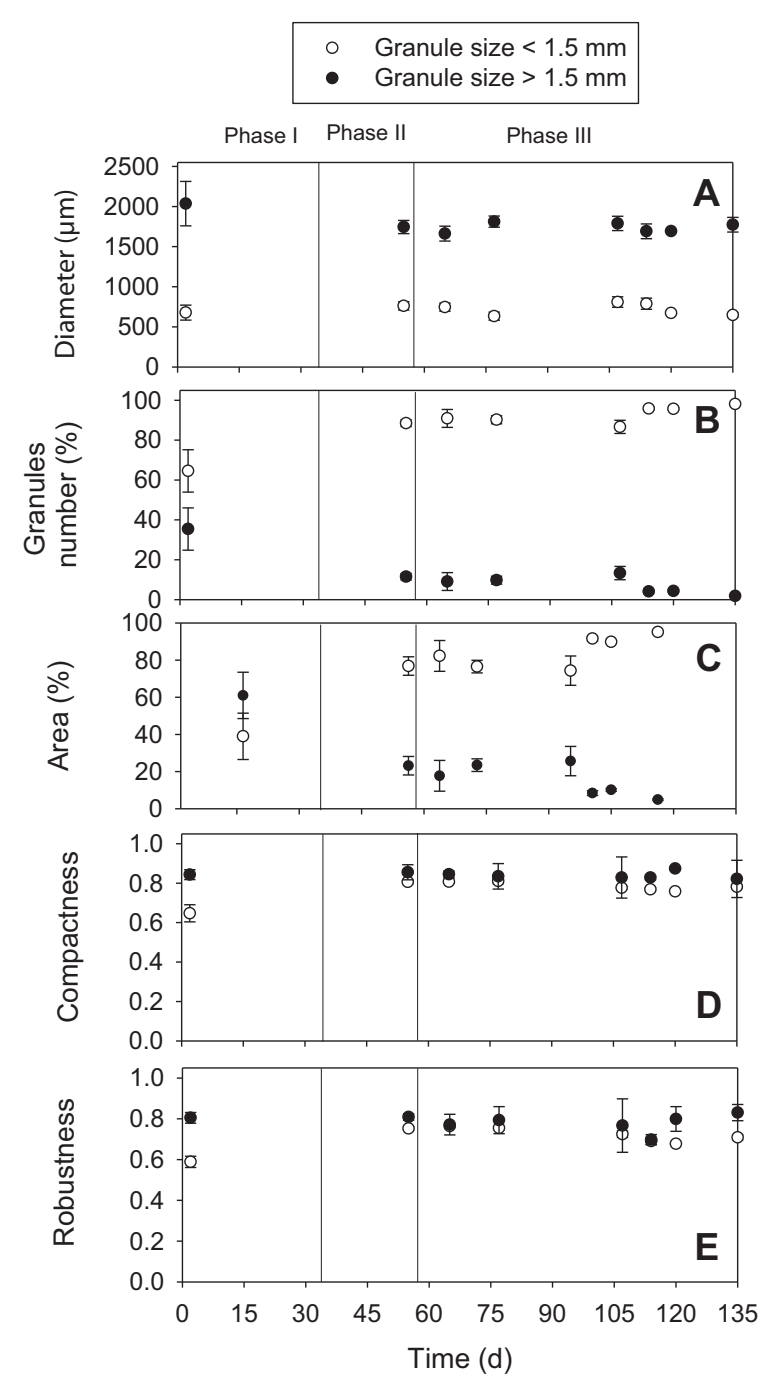

Fig. 2. Diameter (A), granules number (B), area (C), compactness (D) and robustness (E) of aerobic granular biomass during the operational period. The granular sludge was divided into two granule size groups according to its diameter.

\subsection{Bacterial community dynamics}

DGGE analyses were carried out to investigate bacterial community changes in the aerobic granules throughout the reactor operation. The DGGE profile, the cluster analysis and the Shannon and equitability indexes are shown in Fig. 3. The DGGE fingerprint showed that the band patterns changed throughout SBR operation. The number of DGGE bands per sampling day varied between 10 (day-0) and 19 (day-55). Therefore, the bacterial composition on the initial inoculum had a lower diversity, as corroborated by its $\mathrm{H}$ value of 0.90 . Moreover, bands present on day- 0 tended to decrease in their intensity over time, indicating that changes in the relative proportions of such species occurred. Also, some new bands appeared during the reactivation process. Because distinct banding patterns were observed within different sampling days, cluster analysis was performed using the UPGMA algorithm (Fig. 3). The bacterial assemblage indicated that the largest change was observed between samples collected at day-0 and day-35 (after the reactivation of nitrification). In fact, the bacterial population on the initial inoculum (day-0) only presented ca. $25 \%$ of similarity to that on day-35. From the DGGE profile, it is apparent that the number of bands on day- 35 was higher than that on day- 0 , which is corroborated by the increase in the $\mathrm{H}$ value during the 
A

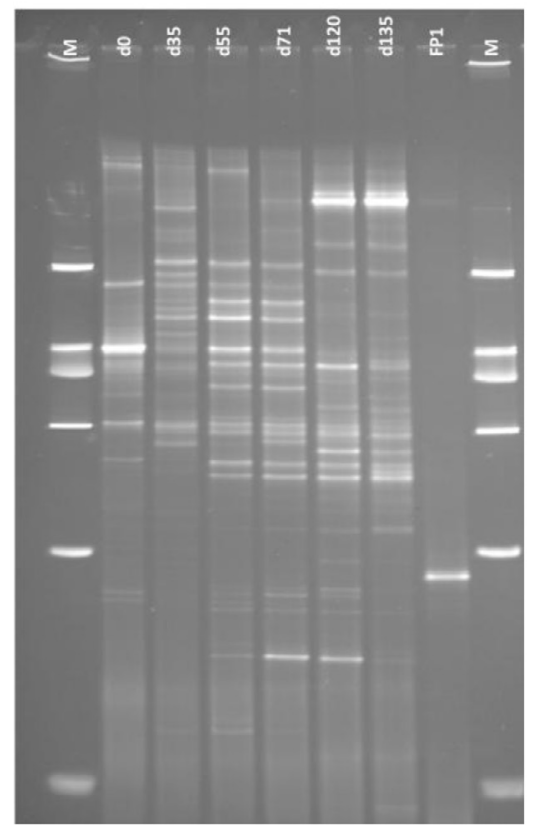

\begin{tabular}{lllll}
\multicolumn{2}{c}{ Similarity (\%) } \\
\end{tabular}

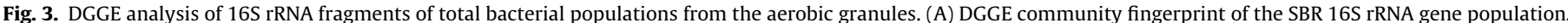

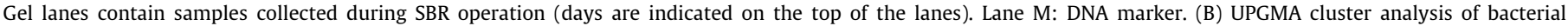

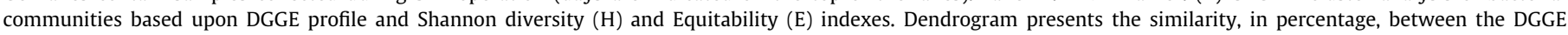
samples. The $\mathrm{H}$ and $\mathrm{E}$ indexes calculated for each sampling day are included along the respective lane.

Table 2

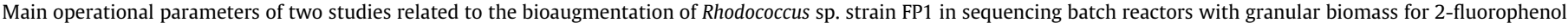
biodegradation.

\begin{tabular}{|c|c|c|}
\hline & Duque et al. (2011) & This study \\
\hline SBR volume & $2.5 \mathrm{~L}$ & $2.1 \mathrm{~L}$ \\
\hline Settling time & $20 \min$ & $10 \min$ \\
\hline Initial inoculum & Activated sludge from a municipal WWTP & Aerobic granules from an industrial WWTP \\
\hline Ability of the inoculum to biodegrade 2-FP & No & No \\
\hline Ability of the inoculum to biodegrade aromatics & No & Yes \\
\hline \multirow[t]{2}{*}{ Bioaugmentation dosage of Rhodococcus sp. strain FP1 } & $\mathrm{V}=1.25 \mathrm{~L}$ & $\mathrm{~V}=0.33 \mathrm{~L}$ \\
\hline & $\mathrm{OD}_{600}=0.80$ & $\mathrm{OD}_{600}=0.66$ \\
\hline
\end{tabular}

reactivation period, indicating that the bacterial population inhabiting the granules changed to a more diverse population. The $\mathrm{H}$ value continued to increase until day-55 (just before bioaugmentation), attaining the maximum $\mathrm{H}$ value of 1.19. After bioaugmentation as the beginning of feeding with 2-FP, the $\mathrm{H}$ indexes decreased, indicating that the species richness within the granules was decreasing over time, probably because of the selective pressure due to the 2-FP loading. Also, from day-71 to day-120, a clear shift in community composition was evident (ca. $40 \%$ of similarity), which coincided with the improvement of 2-FP degradation. Concerning the $\mathrm{E}$ index, it varied between 0.85 and 0.97 , indicating a relative equal abundance of all species in each sampling day, thus an almost uniform distribution of species, in terms of abundance, within the granules.

After bioaugmentation, the DGGE band corresponding to Rhodococcus sp. strain FP1 could not be identified in any of the analysed samples: day-71 (15 days after bioaugmentation), day120 (64 days after bioaugmentation) and day-135 (end of the experimental period). One possible explanation might be a low DNA content of this strain in relation to the total bacterial community within granules, since in general, only sequences corresponding to microorganisms that represent at least $0.5-1 \%$ of the total cells are detectable by DGGE (Muyzer et al., 1993). This result demonstrates that this strain was not dominant in the bacterial community. Indeed, Duque et al. (2011) reported the retrieval of the bioaugmented strain as identified by DGGE in a successful bioaugmentation with FP1 in an aerobic granular reactor with simultaneous removal of acetate and 2-FP. Differences in the main operational parameters of both studies could have contributed to the observed result (Table 2). Firstly, washout of the strain FP1 added in this study could have occurred due to the short settling time applied in the SBR (10 min), because FP1 was a floccular biomass. In the study conducted by Duque et al. (2011), the settling time was $20 \mathrm{~min}$ and probably the floccular FP1 strain could have been more effectively retained in the reactor than that in this study. Secondly; the dosage of FP1 added by Duque et al. (2011) was significantly higher than that applied in this study (Table 2). Martín-Hernández et al. (2012), demonstrated that the dosage is a key factor for a successful bioaugmentation strategy to achieve degradation of phenolic compounds. The difference in the dosage of FP1 could explain the success in the detection of the bioaugmented strain in Duque et al. (2011).

Nevertheless, besides FP1, the bacterial population inhabiting the granules could also have contributed to the degradation of 2FP. The granules used as initial inoculum were collected from a reactor treating an industrial wastewater containing aromatic 
compounds (phenol, o-cresol and quinoline). Thus, probably the indigenous bacterial population in those granules could efficiently adapt to the presence of the toxic compound, and eventually to degrade it. Successful cases of acclimatisation to toxic compounds such as phenol (Tay et al., 2005) or more recalcitrant compounds such as 2,4-dicholorophenol (Wang et al., 2007) and $p$ nitrophenol (Yi et al., 2006) have been reported. Moreover, the presence of aromatics-degraders could have also contributed to the failure in the detection of FP1 by DGGE. Both bacterial populations, FP1 and aromatics-degraders in the granules, had to compete for a sole and scarce carbon source, 2-FP, and this competition happened under the stress of the settling time applied in the SBR. In that way, the aromatics-degraders within the granules could have won the competition because they could remain in the SBR, whilst the floccular FP1 biomass could have been washed-out.

\subsection{Microbial composition within the aerobic granules}

For a further understanding of the bacterial population in the aerobic granules, a pyrosequencing analysis was carried out for the aerobic granules at the beginning (day-0) and at the end of the operation of the SBR (day-135). Fig. 4 summarises the phylogenetic distribution of the bacterial population at class level. Microbial diversity at genus level is presented in Fig. S2 of the Supporting information. In the aerobic granules used as inoculum (day-0), Alphaproteobacteria, Betaproteobacteria and Flavobacteriia were the main identified classes, representing $79 \%$ of the total reads. OTUs affiliated with such classes are commonly found in the microbial community within granules, often representing key bacterial groups (Lv et al., 2014). Aerobic granules are formed by the self-aggregation of flocculent biomass, when proper operational conditions are applied. Former works revealed that during the granulation process, activate sludge flocs assemble and agglomerate as dense and compact granular sludge and although bioflocs had higher biodiversity than granules, the bacterial population did not shift significantly (Lv et al., 2014; Zhou et al., 2014). Also, both works noted that the abundance of members belonging to the Flavobacteriia class increases during the granulation. Members of this phylogenetic division are reported to contribute towards the production of extracellular polymers that allow to bind cells together ( $\mathrm{Li}$ et al., 2014). Moreover, their distribution in the granules outer spherical shell combined with the layered structure of granules, are in part responsible for the higher tolerance of granules to toxics, compared with the activated flocs (Ding et al., 2015; Lv et al., 2014). At genus level, Aquamicrobium (16\%), unclassified Bradyrhizobiaceae (14\%), unclassified Xanthomonadaceae (10\%), Nitrosomonas (10\%), unclassified Flavobacteriaceae (7\%) and unclassified Phyllobacteriaceae (5\%) were mainly detected. Alphaproteobacteria and Betaproteobacteria are abundant classes in the treatment of toxic/recalcitrant organic compounds, such as polycyclic aromatic hydrocarbons and polychlorinated biphenyls (Pérez-Leblic et al., 2012), coal gasification wastewaters (Jia et al., 2016), coking wastewaters (Ma et al., 2015) and complex industrial wastewaters (Ibarbalz et al., 2013). At genus level, the most abundant genera in the inoculum (Aquamicrobium and unclassified Bradyrhizobiaceae) have been previously described as phenolics-degraders (Jiang et al., 2016; Ma et al., 2015). The presence of such microorganisms in the initial inoculum is an indication that probably phenolics degrading bacteria where among the indigenous bacterial population. Regarding nitrification, only a species of ammonia oxidising bacteria (AOB) was detected in the initial inoculum (Nitrosomonas genus), whilst NOB were not detected. The biomass used as initial seed was collected from an aerobic granular reactor performing simultaneous partial nitrification and organic matter removal, discharging an effluent with $95 \%$ of nitrite and $5 \%$ of nitrate which can explain the absence of NOB (Ramos et al., 2016a). Nitrosomonas genus has been previously detected in the treatment of complex wastewater composed of ammonium and aromatic compounds (Jia et al., 2016; Ma et al., 2015; Ramos et al., 2016a). In this way, pyrosequencing analysis shows that the bacterial population of the aerobic granules used as inoculum probably had the ability to perform partial nitrification and biodegradation of phenolic compounds.

At the end of operation (day-135), the main classes were Alphaproteobacteria, Betaproteobacteria and Actinobacteria, representing $76 \%$ of the total reads. Although there was a slight reduction on the relative abundance, members from the Alpha and Beta subdivision of Proteobacteria were present at the beginning and end operation. This indicated that most of microorganisms belonging to these classes could persist within the system. On the contrary, members belonging to the classes Flavobacteriia and Deinococci were no longer detected at the end of operation. Nevertheless, other classes have emerged such as Acidobacteria_Gp4, Gemmatimonadetes, Bacilli and Clostridia. Previous studies on the microbial community composition in activated sludge systems found that class Acidobacteria-Gp4 was more abundant on the processes treating industrial wastewaters than on those treating domestic wastewater (Ibarbalz et al., 2013). Moreover, EPS production has been frequently reported in cultured Acidobacteria species and genes for EPS biosynthesis were found on genomes from Acidobacteria subdivision 1 (Kielak et al., 2016). Nevertheless, it is still unknown if this is a general feature of the Acidobacteria phylum. Despite being frequently detected in wastewater treatment processes, the role of such microorganism in the treatment process is quite limited probably due the difficulties in the cultivation of these bacteria by classical approaches.

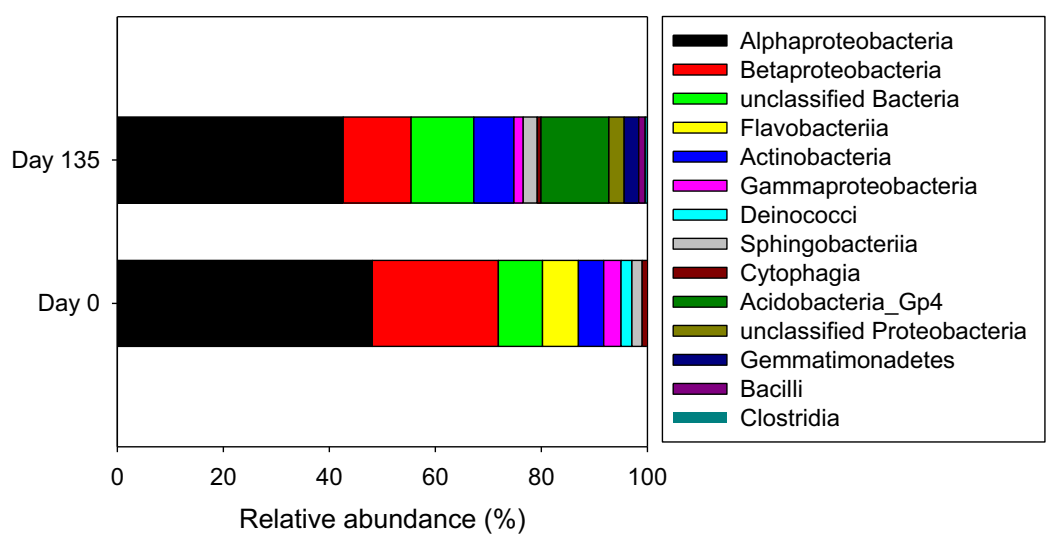

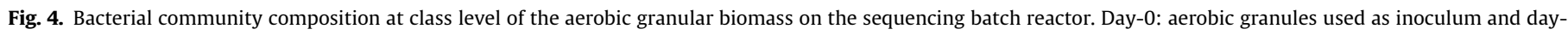
135: aerobic granules performing simultaneous partial nitrification and 2-fluorophenol biodegradation. 
Although on day-0 and day-135 the main represented classes were the same (Alphaproteobacteria and Betaproteobacteria), some new classes have emerged and others detected at day- 0 disappeared. Therefore, a change in the microbial population happened throughout the operational period. The observed differences could not be exclusively attributed due to the 2-FP loading. As revealed by DGGE (section 3.3), a dynamic bacterial population was present throughout the different phases, independently of the toxic compound presence. The variation of the bacterial community composition probably resulted from the adaptation to the conditions in the living environment namely the influent wastewater composition, the load of the toxic compound and the operational conditions. Nevertheless, the impact of the load of toxic compounds in the bacterial population is well documented in the literature (Amorim et al., 2014; Duque et al., 2015; Ramos et al., 2015).

At genus level, unclassified Bacteria (13\%), unclassified Rhizobiales (11\%), unclassified Bradyrhizobiaceae (10\%), unclassified Alphaproteobacteria (10\%), unclassified Acidobacteria_Gp4 (8\%), Nitrobacter (8\%) and Nitrosomonas (7\%) were mainly detected. Acidobacteria_Gp4 and Actinobacteria classes have been detected in the treatment of other complex industrial wastewaters (Ibarbalz et al., 2013; Jia et al., 2016). More specifically, Rhizobiales (Carvalho et al., 2006) and Acidobacteria_Gp4 genera (Ibarbalz et al., 2013; Jia et al., 2016; Pérez-Leblic et al., 2012) have been previously detected in bioreactors treating wastewaters containing aromatic compounds. Therefore, pyrosequencing also suggests the presence of phenolic compounds degraders within the aerobic granules at day- 135 .

Regarding bacteria involved in nitrification process, Nitrosomonas (7\%) and Nitrobacter (8\%) genera were detected in the aerobic granules at day-135. The presence of both bacteria was expected because nitrite and nitrate were detected in the SBR effluent. Nitrosomonas is an AOB-genus and, therefore, is related to the oxidation of ammonium to nitrite. The relative abundance of Nitrosomonas genus at day-135 was slightly lower (7\%) than that in the initial inoculum (10\%). This reduction could be due to the 2 -FP load since nitrifiers are mainly distributed in the granules outer layer, which in turn is more exposed to the toxic stress than bacteria in the inner core. Nitrobacter is a NOB-genus and, therefore, it is involved on the oxidation of nitrite to nitrate. The pyrosequencing analysis did not detect the presence of Nitrobacter on day-0, possibly because its amount was undetectable by pyrosequencing. Probably Nitrobacter genus proliferated in the SBR during the reactivation phase (phase I), since most of the ammonium was oxidised to nitrate during phase II. In spite of that, the relative abundance of Nitrosomonas (7\%) and Nitrobacter (8\%) genera was very similar at day-135, during which the nitrogen in the effluent of the SBR was mainly in the form of nitrite (79\%) and not nitrate (21\%). This suggests that the strategy to repress the NOB activity based on the maintenance of a low [DO]/[N-NH $\left.\mathrm{NH}_{4}^{+}\right]$ratio in the SBR partially worked. Probably a better control of the $[\mathrm{DO}] /\left[\mathrm{N}-\mathrm{NH}_{4}^{+}\right]$ ratio in the SBR was necessary to completely repress the NOB activity, and wash them out from the reactor.

In addition, Rhodococcus genus was detected at day-135, which could be due to the bioaugmentation with the 2-FP specialized degrading strain. From the DGGE it was not possible to infer on the presence of the added Rhodococcus sp. FP1 but by pyrosequencing analysis, which allows to analyze the microbial diversity in more depth, the presence of phylotypes of the genus Rhodococcus was observed. However, it was not possible to characterise these microorganisms at species level and hence ascertain the presence of the added strain within the system. According to the relative abundance in the pyrosequencing analysis and the abilities of each bacterial genus described in the literature, unclassified Rhizobiales, unclassified Bradyrhizobiaceae and unclassified Acidobacteria_Gp4 genera together with the Rhodococcus species could be the phenolics-degrading populations involved in the 2-FP biodegradation at day-135.

\section{Conclusions}

Simultaneous nitritation and biodegradation of 2-fluorophenol was achieved in an aerobic granular SBR. The robustness, compactness and settling properties of the aerobic granules were maintained almost constantly over time, which is in accordance with the removal efficiency in the bioreactor.

Molecular biology analysis showed a change in the bacterial diversity throughout the operational period. The presence of Rhodococcus genus members at the end of operation could be due to the bioaugmentation process and such microorganisms together with other potential phenolics degrading microorganisms were probably involved in the 2-FP degradation. Nitrosomonas persisted throughout bioreactor operation, albeit its relative abundance slightly decreased.

\section{Acknowledgements}

This work was supported by Portuguese Funds from FCT - Fundação para a Ciência e a Tecnologia through the strategic funding of UID/Multi/ 50016/2013 and UID/BIO/04469/2013 units and COMPETE 2020 (POCI-01-0145-FEDER-006684) and Spanish Funds from Ministerio de Educación y Ciencia through the ONLYBIO project (CTQ2011-24745/PPQ). C.L. Amorim and D.P Mesquita wish to acknowledge the research grant from FCT (Ref. SFRH/ $\mathrm{BPD} / 96481 / 2013$ and SFRH/BPD/82558/2011, respectively). C. Ramos wants to thank the Universitat Autònoma de Barcelona for his internship grant. The authors also thank to COST Action ES1202: Conceiving Wastewater Treatment in 2020 - Energetic, environmental and economic challenges; BioTecNorte operation (NORTE-01-0145-FEDER-000004) funded by the European Regional Development Fund under the scope of Norte2020 - Programa Operacional Regional do Norte; and to TRITON thematic network (316RT0508) from the CYTED Programme. Thanks to Dr R.C. Pullar for helping to edit the English.

\section{Appendix A. Supplementary data}

Supplementary data associated with this article can be found, in the online version, at http://dx.doi.org/10.1016/j.biortech.2017.03. 173.

\section{References}

Adav, S.S., Lee, D.-J., Show, K.-Y., Tay, J.-H., 2008. Aerobic granular sludge: recent advances. Biotechnol. Adv. 26, 411-423. http://dx.doi.org/10.1016/j. biotechadv.2008.05.002.

Al-Khalid, T., El-Naas, M.H., 2012. Aerobic biodegradation of phenols: a comprehensive review. Crit. Rev. Environ. Sci. Technol. 42, 1631-1690. http:// dx.doi.org/10.1080/10643389.2011.569872.

Amorim, C.L., Maia, A.S., Mesquita, R.B.R., Rangel, A.O.S.S., van Loosdrecht, M.C.M., Tiritan, M.E., Castro, P.M.L., 2014. Performance of aerobic granular sludge in a sequencing batch bioreactor exposed to ofloxacin, norfloxacin and ciprofloxacin. Water Res. 50, 101-113. http://dx.doi.org/10.1016/j. watres.2013.10.043.

APHA, 1999. Standard Methods for the Examination of Water and Wastewater. Stand. Methods 541.

Bartrolí, A., Pérez, J., Carrera, J., 2010. Applying ratio control in a continuous granular reactor to achieve full nitritation under stable operating conditions. Environ. Sci. Technol. 44, 8930-8935. http://dx.doi.org/10.1021/es1019405.

Bartrolí, A., Carrera, J., Pérez, J., 2011. Bioaugmentation as a tool for improving the start-up and stability of a pilot-scale partial nitrification biofilm airlift reactor. Bioresour. Technol. 102, 4370-4375. http://dx.doi.org/10.1016/j. biortech.2010,12.084.

Caldeira, M., Heald, S.C., Carvalho, M.F., Vasconcelos, I., Bull, A.T., Castro, P.M.L., 1999. 4-Chlorophenol degradation by a bacterial consortium: development of a 
granular activated carbon biofilm reactor. Appl. Microbiol. Biotechnol. 52, 722729. http://dx.doi.org/10.1007/s002530051584.

Carvalho, M.F., Ferreira, M.I.M., Moreira, I.S., Castro, P.M.L., Janssen, D.B., 2006. Degradation of fluorobenzene by Rhizobiales strain F11 via ortho cleavage of 4fluorocatechol and catechol. Appl. Environ. Microbiol. 72, 7413-7417. http://dx. doi.org/10.1128/AEM.01162-06.

Chaojie, Z., Qi, Z., Ling, C., Yuan, Y., Hui, Y., 2007. Degradation of monofluorophenols by an acclimated activated sludge. Biodegradation 18, 51-61. http://dx.doi.org/10.1007/s10532-005-9035-5.

Ding, Z., Bourven, I., Guibaud, G., van Hullebusch, E.D., Panico, A., Pirozzi, F., Esposito, G., 2015. Role of extracellular polymeric substances (EPS) production in bioaggregation: application to wastewater treatment. Appl. Microbiol. Biotechnol. 99, 9883-9905. http://dx.doi.org/10.1007/s00253-015-6964-8.

Duque, A.F., Bessa, V.S., Carvalho, M.F., de Kreuk, M.K., van Loosdrecht, M.C.M., Castro, P.M.L., 2011. 2-Fluorophenol degradation by aerobic granular sludge in a sequencing batch reactor. Water Res. 45, 6745-6752. http://dx.doi.org/10.1016/ j.watres.2011.10.033.

Duque, A.F., Hasan, S.A., Bessa, V.S., Carvalho, M.F., Samin, G., Janssen, D.B., Castro, P. M.L. 2012. Isolation and characterization of a Rhodococcus strain able to degrade 2-fluorophenol. Appl. Microbiol. Biotechnol. 95, 511-520. http://dx.doi. org/10.1007/s00253-011-3696-2.

Duque, A.F., Bessa, V.S., Castro, P.M.L., 2015. Characterization of the bacterial communities of aerobic granules in a 2-fluorophenol degrading process. Biotechnol. Rep. 5, 98-104. http://dx.doi.org/10.1016/j.btre.2014.12.007.

Ibarbalz, F.M., Figuerola, E.L.M., Erijman, L., 2013. Industrial activated sludge exhibit unique bacterial community composition at high taxonomic ranks. Water Res. 47, 3854-3864. http://dx.doi.org/10.1016/j.watres.2013.04.010.

Isanta, E., Reino, C., Carrera, J., Pérez, J., 2015. Stable partial nitritation for lowstrength wastewater at low temperature in an aerobic granular reactor. Water Res. 80, 149-158. http://dx.doi.org/10.1016/j.watres.2015.04.028.

Jemaat, Z., Suárez-Ojeda, M.E., Pérez, J., Carrera, J., 2013. Simultaneous nitritation and p-nitrophenol removal using aerobic granular biomass in a continuous airlift reactor. Bioresour. Technol. 150, 307-313. http://dx.doi.org/10.1016/j. biortech.2013.10.005.

Jemaat, Z., Suárez-Ojeda, M.E., Pérez, J., Carrera, J., 2014. Partial nitritation and ocresol removal with aerobic granular biomass in a continuous airlift reactor. Water Res. 48, 354-362. http://dx.doi.org/10.1016/j.watres.2013.09.048.

Jia, S., Han, H., Zhuang, H., Hou, B., 2016. The pollutants removal and bacterial community dynamics relationship within a full-scale British Gas/Lurgi coal gasification wastewater treatment using a novel system. Bioresour. Technol. 200, 103-110. http://dx.doi.org/10.1016/j.biortech.2015.10.005.

Jiang, Y., Wei, L., Zhang, H., Yang, K., Wang, H., 2016. Removal performance and microbial communities in a sequencing batch reactor treating hypersaline phenol-laden wastewater. Bioresour. Technol. 218, 146-152. http://dx.doi.org/ 10.1016/j.biortech.2016.06.055.

Key, B.D., Howell, R.D., Criddle, C.S., 1997. Fluorinated Organics in the Biosphere. Environ. Sci. Technol. 31, 2445-2454. http://dx.doi.org/10.1021/es961007c.

Kielak, A.M., Barreto, C.C., Kowalchuk, G.A., van Veen, J.A., Kuramae, E.E., 2016. The ecology of acidobacteria: moving beyond genes and genomes. Front. Microbiol. 7, 1-16. http://dx.doi.org/10.3389/fmicb.2016.00744.

Kim, S.-S., Kim, H.-J., 2003. Impact and threshold concentration of toxic materials in the stripped gas liquor on nitrification. Korean J. Chem. Eng. 20, 1103-1110. http://dx.doi.org/10.1007/BF02706944.

Li, J., Ding, L. .Bin., Cai, A., Huang, G.X., Horn, H., 2014. Aerobic sludge granulation in a full-scale sequencing batch reactor. Biomed Res. Int. http://dx.doi.org/ $10.1155 / 2014 / 268789$

Liu, Y.-Q., Tay, J.-H., Ivanov, V., Moy, B.Y.-P., Yu, L., Tay, S.T.-L., 2005. Influence of phenol on nitrification by microbial granules. Process Biochem. 40, 3285-3289. http://dx.doi.org/10.1016/j.procbio.2005.03.018.
Lv, Y., Wan, C., Lee, D.J., Liu, X., Tay, J.H., 2014. Microbial communities of aerobic granules: granulation mechanisms. Bioresour. Technol. 169, 344-351. http://dx. doi.org/10.1016/j.biortech.2014.07.005.

Ma, Q., Qu, Y., Shen, W., Zhang, Z., Wang, J., Liu, Z., Li, D., Li, H., Zhou, J., 2015. Bacterial community compositions of coking wastewater treatment plants in steel industry revealed by Illumina high-throughput sequencing. Bioresour. Technol. 179, 436-443. http://dx.doi.org/10.1016/j.biortech.2014.12.041.

Martín-Hernández, M., Suárez-Ojeda, M.E., Carrera, J., 2012. Bioaugmentation for treating transient or continuous p-nitrophenol shock loads in an aerobic sequencing batch reactor. Bioresour. Technol. 123, 150-156. http://dx.doi.org/ 10.1016/j.biortech.2012.07.014.

Mesquita, D.P., Dias, O., Dias, A.M.A., Amaral, A.L., Ferreira, E.C., 2009. Correlation between sludge settling ability and image analysis information using partial least squares. Anal. Chim. Acta 642, 94-101. http://dx.doi.org/10.1016/j. aca.2009.03.023.

Milia, S., Cappai, G., Perra, M., Carucci, A., 2012. Biological treatment of nitrogen-rich refinery wastewater by partial nitritation (SHARON) process. Environ. Technol. 33, 1477-1483. http://dx.doi.org/10.1080/09593330.2012.660651.

Morita, M., Kudo, N., Uemoto, H., Watanabe, A., Shinozaki, H., 2007. Protective effect of immobilized ammonia oxidizers and phenol-degrading bacteria on nitrification in ammonia- and phenol-containing wastewater. Eng. Life Sci. 7 587-592. http://dx.doi.org/10.1002/elsc.200700014.

Muyzer, G., de Waal, E.C., Uitterlinden, A.G., 1993. Profiling of complex microbial populations by denaturing gradient gel electrophoresis analysis of polymerase chain reaction-amplified genes coding for 16S rRNA. Appl. Environ. Microbiol 59, 695-700.

Pérez-Leblic, M.I., Turmero, A., Hernández, M., Hernández, A.J., Pastor, J., Ball, A.S., Rodríguez, J., Arias, M.E., 2012. Influence of xenobiotic contaminants on landfill soil microbial activity and diversity. J. Environ. Manage. 95, S285-S290. http:// dx.doi.org/10.1016/j.jenvman.2010.07.017.

Ramos, C., Suárez-Ojeda, M.E., Carrera, J., 2015. Long-term impact of salinity on the performance and microbial population of an aerobic granular reactor treating a high-strength aromatic wastewater. Bioresour. Technol. http://dx.doi.org/ 10.1016/j.biortech.2015.09.084.

Ramos, C., Suárez-Ojeda, M.E., Carrera, J., 2016a. Biodegradation of a high-strength wastewater containing a mixture of ammonium, aromatic compounds and salts with simultaneous nitritation in an aerobic granular reactor. Process Biochem. 51, 399-407. http://dx.doi.org/10.1016/j.procbio.2015.12.020.

Ramos, C., Suárez-Ojeda, M.E., Carrera, J., 2016b. Denitritation in an anoxic granular reactor using phenol as sole organic carbon source. Chem. Eng. J. 288, 289-297. http://dx.doi.org/10.1016/j.cej.2015.11.099.

Reino, C., Suárez-Ojeda, M.E., Pérez, J., Carrera, J., 2016. Kinetic and microbiological characterization of aerobic granules performing partial nitritation of a lowstrength wastewater at 10 \& \#xB0;C. Water Res. 101, 147-156. http://dx.doi. org/10.1016/j.watres.2016.05.059.

Tay, S.T.-L., Moy, B.Y.-P., Jiang, H.-L., Tay, J.-H., 2005. Rapid cultivation of stable aerobic phenol-degrading granules using acetate-fed granules as microbial seed. J. Biotechnol. 115, 387-395. http://dx.doi.org/10.1016/j.jbiotec.2004.09.008.

Wang, S.-G., Liu, X.-W., Zhang, H.-Y., Gong, W.-X., Sun, X.-F., Gao, B.-Y., 2007 Aerobic granulation for 2,4-dichlorophenol biodegradation in a sequencing batch reactor. Chemosphere 69, 769-775. http://dx.doi.org/10.1016/j. chemosphere.2007.05.026.

Yi, S., Zhuang, W.-Q., Wu, B., Tay, S.T.-L., Tay, J.-H., 2006. Biodegradation of pnitrophenol by aerobic granules in a sequencing batch reactor. Environ. Sci. Technol. 40, 2396-2401. http://dx.doi.org/10.1021/es0517771.

Zhou, D., Niu, S., Xiong, Y., Yang, Y., Dong, S., 2014. Microbial selection pressure is not a prerequisite for granulation: dynamic granulation and microbial community study in a complete mixing bioreactor. Bioresour. Technol. 161, 102-108. http://dx.doi.org/10.1016/j.biortech.2014.03.001. 